\title{
Children in Monetary Poor Households: Baseline and COVID-19 Impact for 2020 and 2021
}

\author{
Oliver Fiala ${ }^{1}$ - Enrique Delamónica ${ }^{2} \cdot$ Gerardo Escaroz $^{3} \cdot$ Ismael Cid Martinez $^{2,4}$. \\ José Espinoza-Delgado ${ }^{2,5} \cdot$ Aristide Kielem $^{2}$
}

Received: 18 September 2020 / Accepted: 6 March 2021 / Published online: 11 May 2021

(c) The Author(s), under exclusive licence to Springer Nature Switzerland AG 2021

\begin{abstract}
The impact of the global economic crisis caused by the COVID-19 pandemic will not affect all children equally: those in poorer households and children who are disadvantaged face the most serious consequences. As parents lose their jobs and incomes, the impact on children living in impoverished households must be measured. In this article, we assess the economic consequences of the pandemic on these children. Given that poorer families have a larger number of children than other families, the analysis first establishes the proportion of children living in monetary poor households, as defined by national standards, across developing countries. Then, using historical changes and trends of income distribution per country, the latest projections about economic decline due to the pandemic, and demographic information about the distribution of children by deciles, we estimate the expected increase in the number of children in monetary poor households in developing countries as of end of 2020 to be an additional 122-144 million and, at best, a moderate decline in these numbers by end of 2021 .
\end{abstract}

Keywords Child poverty $\cdot$ Monetary poverty $\cdot$ National poverty lines $\cdot$ Children $\cdot$ Income distribution - Economic shocks · COVID-19

The opinions in this paper are sole responsibility of the authors and should not be taken as the official stance of the respective organizations.

This article is part of the Topical Collection on Economics of COVID-19

Enrique Delamónica

edelamonica@unicef.org

Save the Children, London, UK

2 UNICEF, New York City, NY, USA

3 UNICEF, Latin America and Caribbean Regional Office, New York City, NY, USA

4 New School for Social Research, New York, NY, USA

5 University of Göttingen, Göttingen, Germany 


\section{Introduction}

Children suffer poverty differently from adults. Their needs, in order to survive and thrive are different, their dreams and hopes are different, and their necessities ought to be supported and taken care of by adults, not by themselves (Barnes and Wright 2012; Boyden et al. 2012; Jones and Sumner 2011; Lyytikäinen et al. 2006; Nieuwenhuys 1994; Wordsworth et al. 2005). Thus, when measuring child poverty, it is important to use a direct multidimensional measurement. Nevertheless, in the context of COVID-19 and its aftermath, children's families are suffering from sharp reductions in employment and income. These developments also affect children negatively and can lead to a violation of their right to a minimum standard of living. Consequently, in this article we measure the situation of children indirectly by the level of consumption/income of the household.

First, we assess that prior to COVID-19 one out of three children lived in monetary poor households (henceforth MPHs) based on national poverty lines in developing countries. This is, to our knowledge, the first time such an estimate has been carried out. Then, we project there could be between 122 and 144 million additional children living in MPHs by the end of 2020 (compared to 2019). Moreover, there could be between 80 and 144 million additional children in these circumstances by the end of 2021 .

We use, country-by-country, the prevalence of monetary poverty based on national poverty lines from the World Bank database, GDP growth projections for 2020 and 2021 from the IMF and the World Bank, and population growth projections from the UN Population Division. As, in general, poorer households have more children, we use household survey data (from Multiple Indicator Cluster Surveys and Demographic and Health Surveys) to arrive at the share of children per wealth decile. We combine this information with likely changes in income distribution of varying strength (based on historical trends from the UNU WIDER database) to establish a range of possible paths for the percentage and number of children in MPHs.

Ours is one of the few simulations of changes in monetary poverty due to COVID-19 that takes income distribution fluctuations into account (i.e. we do not linearly translate projected declines in per capita income in the country to all households). Moreover, it is the only estimate we know that uses country specific data on income distribution by country (as opposed to a generic assumption about changes in Gini across countries).

Besides this introduction, the article is structured as follows. First, we describe the main results and sources of data. This is followed by an explanation about how the baseline (the "pre-COVID" situation) was estimated and how the simulations were carried out. The assumptions (included discarded ones) and models used to estimate the impact of COVID-19 are explained. The paper closes with a few conclusions and suggestions for further research.

\section{Main Results}

The first column in Table 1 shows both the prevalence and the absolute number of children living in MPHs prior to the onset of COVID-19. ${ }^{1}$ Our estimate suggests that a third of children (i.e. about 591 million children) in developing countries were living in families in monetary poverty based on national poverty lines.

\footnotetext{
1 The global headcount rate does not include China.
} 
Without urgent action to protect families from the financial hardships caused by COVID-19 and its containment measures, the share of children living in households that cannot make ends meet in developing countries ${ }^{2}$ could reach 37.7-38.9 per cent in 2020 (Table 1). This is equivalent to a total number of children living in MPHs between 713 and 735 million, an increase of between 122 and 144 million in comparison to the baseline (Table 1).

Although the 5-7 percentage point increase in the prevalence of children living in MPHs may seem small, it represents an increase of about 24 percent in the number of additional children. The countries across Eastern Europe and Central Asia, as well as East Asia and Pacific could see the most significant increase in absolute numbers, with an increase by 50-55 per cent. ${ }^{3}$ Figure 1 illustrates the increase in prevalence of children living in MPHs globally, caused by the worsening economic situation and the changes in the underlying income distribution.

We also use economic projections for 2021 to extend our estimates on children living in MPHs to that year. The estimate comes with a large degree of uncertainty, as illustrated in Fig. 1.

Table 2 shows the projected prevalence and total number of children living in poverty in 2021. With GDP projections only showing to a moderate recovery in many countries and increasing child populations, we do not expect to see the number of children in monetary poor families to decrease to pre-crisis level in the following year. Our estimates suggest a global headcount rate between 35 and 39 per cent in 2021, equivalent to 669-735 million children living in MPHs. In the best-case scenario this would be a reduction of 44 million children in comparison to 2020. This means, even in the best-case scenario, we expect a reduction in total number in 2021 , which is about a third of the increase in 2020. In the worst case, both the prevalence rate and absolute numbers might stay the same in comparison to the 2020 level.

Our estimates suggest that East Asia and Pacific (without China) would expect a decline in 2021 (compared to our projected increases in 2020), with prevalence rates in the middle scenario decreasing by 11 percent. Only in South Asia is a reversal between 2020 and 2021 also projected (both in prevalence and absolute numbers). In the other regions (in particular, those with the highest burden of children living in MPHs, such as Sub-Saharan Africa and Latin America and the Caribbean) do not seem to fare better in 2021 than in 2020.

The results from Tables 1 and 2 could be summarized in Fig. 2. There the total change (i.e. the increase and the partial but not compensating reduction) in the number of children in MPHs is shown. According to the middle scenario, for all developing countries, the projection is that by the end of 2021 there would be about 110 million additional children in these households. For the most pessimistic scenario, these numbers would be up to 132-144 million children. However, in the most optimistic outlook, these numbers would be $76-88$ additional million children compared to the pre-COVID situation.

\footnotetext{
2 The countries have been grouped into geographical regions and exclude industrialized countries.

3 This is mainly due to the sheer population size of China, although in percentage terms, both before and after the impact of COVID, the prevalence of children in MPHs is comparatively low.
} 
Table 1 Pre-COVID 19 Baseline and projected prevalence of children living in monetary poor households in 2020

\begin{tabular}{|c|c|c|c|c|c|c|}
\hline \multirow[t]{2}{*}{ Region } & \multirow{2}{*}{$\begin{array}{l}\text { Pre- } \\
\text { COVID } \\
19 \text { base- } \\
\text { line }\end{array}$} & \multicolumn{5}{|c|}{ Projections } \\
\hline & & $\begin{array}{l}\text { Lower } \\
\text { bound } \\
\text { (outer) }\end{array}$ & $\begin{array}{l}\text { Lower } \\
\text { bound } \\
\text { (inner) }\end{array}$ & Middle & $\begin{array}{l}\text { Upper } \\
\text { bound } \\
\text { (inner) }\end{array}$ & $\begin{array}{l}\text { Upper } \\
\text { bound } \\
\text { (outer) }\end{array}$ \\
\hline \multicolumn{7}{|l|}{ Headcount (\%) in 2020} \\
\hline East Asia and Pacific (with China) & 7.9 & 11.6 & 11.9 & 12.1 & 12.1 & 12.3 \\
\hline $\begin{array}{l}\text { East Asia and Pacific (without } \\
\text { China) }\end{array}$ & 16.1 & 17.6 & 18.3 & 18.5 & 18.6 & 19.3 \\
\hline Eastern Europe and Central Asia & 14.1 & 17.5 & 18.8 & 19.1 & 19.4 & 20.9 \\
\hline Latin America and Caribbean & 38.2 & 47.2 & 47.8 & 48.0 & 48.2 & 48.4 \\
\hline Middle East and North Africa & 26.2 & 30.7 & 30.7 & 30.9 & 31.2 & 31.2 \\
\hline South Asia & 28.1 & 36.0 & 36.4 & 36.7 & 37.2 & 37.2 \\
\hline Sub-Saharan Africa & 46.4 & 50.3 & 50.6 & 50.7 & 50.9 & 51.1 \\
\hline WORLD & 32.3 & 37.7 & 38.1 & 38.4 & 38.6 & 38.9 \\
\hline \multicolumn{7}{|l|}{ Absolute number (in million) in 2020} \\
\hline East Asia and Pacific (with China) & 41.2 & 60.0 & 61.5 & 61.9 & 62.4 & 63.8 \\
\hline $\begin{array}{l}\text { East Asia and Pacific (without } \\
\text { China) }\end{array}$ & 35.8 & 38.9 & 40.4 & 40.8 & 41.3 & 42.6 \\
\hline Eastern Europe and Central Asia & 14.6 & 18.3 & 19.7 & 20.0 & 20.3 & 21.9 \\
\hline Latin America and Caribbean & 71.7 & 88.4 & 89.3 & 88.7 & 90.1 & 90.6 \\
\hline Middle East and North Africa & 40.6 & 48.2 & 48.3 & 48.7 & 49.1 & 49.1 \\
\hline South Asia & 173.3 & 221.8 & 224.1 & 226.3 & 228.6 & 229.1 \\
\hline Sub-Saharan Africa & 249.4 & 275.9 & 277.6 & 278.5 & 279.3 & 280.6 \\
\hline WORLD & 590.8 & 712.6 & 720.5 & 725.1 & 729.8 & 735.0 \\
\hline
\end{tabular}

\section{Methodology}

\section{The Baseline}

In order to estimate the proportion of children living in MPHs before COVID-19 across developing countries, we rely on national standards of household poverty, as defined by the proportion of the population living below the national poverty line. ${ }^{4}$ This indicator is reported by the World Bank in its World Development Indicator dataset (World Bank, 2020b).

\footnotetext{
${ }^{4}$ Also see SDG Indicator 1.2.1. (https://unstats.un.org/sdgs/indicators/indicators-list/). This indicator is not strictly comparable across countries. Countries establish monetary poverty lines differently as the cost (and components) of the minimum consumption basket to avoid poverty varies from one context to the next. Nevertheless, the way in which national poverty lines are established are very similar and consistent across countries (starting with the culturally appropriate/accepted diet to reach a minimum caloric intake and adding additional goods and services - either directly or using an Engel's Coefficient). Moreover, using strictly the same monetary value across countries introduces biases. It would be a fluke that the actual cost of the minimum consumption basket would coincide with such a value, meaning that the actual poor in any given country would be under-or over-estimated (and no adjustments in the exchange rates can fix this problem). By using the national poverty lines, we acknowledge the lack of comparability. In addition, the aggregated number should be interpreted as the "global number of households/people classified as poor by each country according to their own national poverty lines".
} 
Fig. 1 Projected prevalence of children living in poor households (headcount), globally (2020 and 2021)

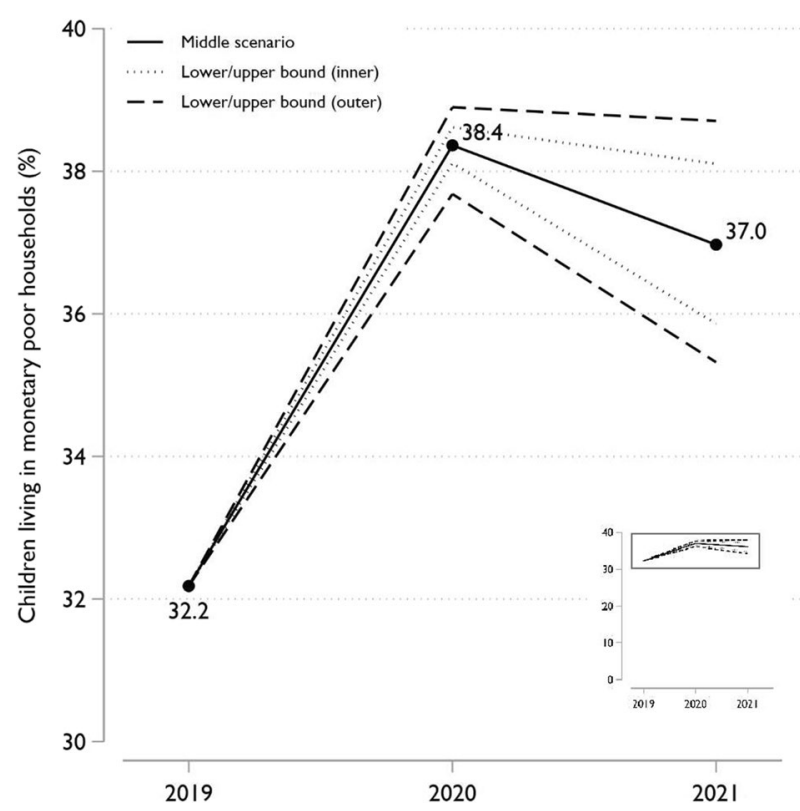

Table 2 Projected prevalence of children living in monetary poor households in 2021

\begin{tabular}{lccccc}
\hline Region & $\begin{array}{l}\text { Lower } \\
\text { bound } \\
\text { (outer) }\end{array}$ & $\begin{array}{l}\text { Lower } \\
\text { bound } \\
\text { (inner) }\end{array}$ & Middle & $\begin{array}{r}\text { Upper } \\
\text { bound } \\
\text { (inner) }\end{array}$ & $\begin{array}{r}\text { Upper } \\
\text { bound } \\
\text { (outer) }\end{array}$ \\
\hline Headcount (\%) in 2021 & & & & & \\
East Asia and Pacific (with China) & 9.5 & 9.8 & 10.2 & 10.6 & 11.0 \\
East Asia and Pacific (without China) & 15.7 & 16.2 & 16.6 & 16.9 & 17.6 \\
Eastern Europe and Central Asia & 15.7 & 16.9 & 17.9 & 19.0 & 21.2 \\
Latin America and Caribbean & 45.2 & 46.1 & 47.1 & 48.2 & 49.0 \\
Middle East and North Africa & 29.7 & 30.0 & 30.8 & 31.6 & 31.8 \\
South Asia & 31.6 & 32.1 & 33.7 & 35.5 & 35.8 \\
Sub-Saharan Africa & 49.4 & 49.9 & 50.8 & 51.7 & 52.3 \\
WORLD & 35.3 & 35.9 & 37.0 & 38.1 & 38.7 \\
Absolute number (in million) in 2021 & & & & & 5.9 \\
East Asia and Pacific (with China) & 49.0 & 50.7 & 52.7 & 54.7 & 56.9 \\
East Asia and Pacific (without China) & 34.8 & 35.8 & 36.6 & 37.4 & 38.9 \\
Eastern Europe and Central Asia & 16.5 & 17.7 & 18.8 & 19.9 & 22.3 \\
Latin America and Caribbean & 84.3 & 85.9 & 87.8 & 89.8 & 91.3 \\
Middle East and North Africa & 47.4 & 47.8 & 49.1 & 50.4 & 50.7 \\
South Asia & 194.4 & 197.4 & 207.7 & 218.3 & 220.4 \\
Sub-Saharan Africa & 276.7 & 279.5 & 284.5 & 289.7 & 293.0 \\
WORLD & 668.4 & 679.0 & 700.7 & 722.8 & 734.6 \\
\hline
\end{tabular}




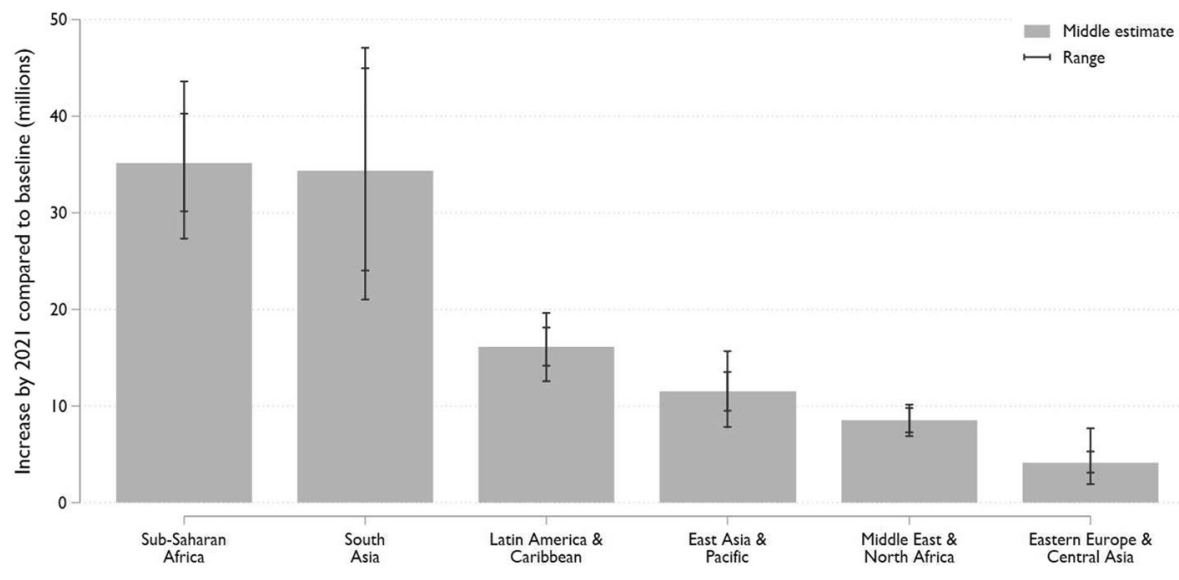

Fig. 2 Regional distribution of the additional 76 to 144 million children projected to be living in monetary poor households by the end of 2021

It is well known that poorer families tend to have more children. ${ }^{5}$ Consequently, it would not be correct to just apply the percentage of children in the total population to obtain the proportion of children among the poor population. We estimate the proportion of children by decile of the wealth distribution in 98 countries by processing Demographic and Health Surveys (DHS, phases VI-VII) and Multi Indicator Cluster Surveys (MICS, rounds 4-6) from 2010 onwards. In MICS and DHS these are wealth (not income/consumption) deciles. Nevertheless, given the data limitations, this is the best available information and allows comparability across countries.

Table 3 shows the data availability of poverty prevalence, income distributions, and population data by region. Our database includes in total 159 countries (which excludes industrialised countries), including 29 low-income countries, 50 lower middle-income countries, 55 upper middle-income countries and 25 high-income countries across six world regions. Also, we can classify countries based on three different types of data:

1) For 104 countries we do have both a baseline of the prevalence of children living in MPHs as well as income distributions to estimate various scenarios.

2) For 18 countries we do have a baseline estimate of the prevalence of children living in poverty, however, we do not have income distributions and are therefore we are not able to estimate the various scenarios for 2020 and 2021.

3) For another 37 we have neither a national poverty headcount for the baseline nor an income distribution.

National poverty lines are not widely available in publicly accessible databases. We could have worked with the useful and carefully constructed list of national poverty lines converted to U\$ PPP (at 2011 values) from Jolliffe and Prydz (2016). However, as a typical example of the difficulties and constraints of data, not all the income and consumption information in the UNU WIDER database are in U\$ PPP 2011 values. This means we

5 This stylized fact is known at least since Roman times, from which the word "proletarian" originates. 


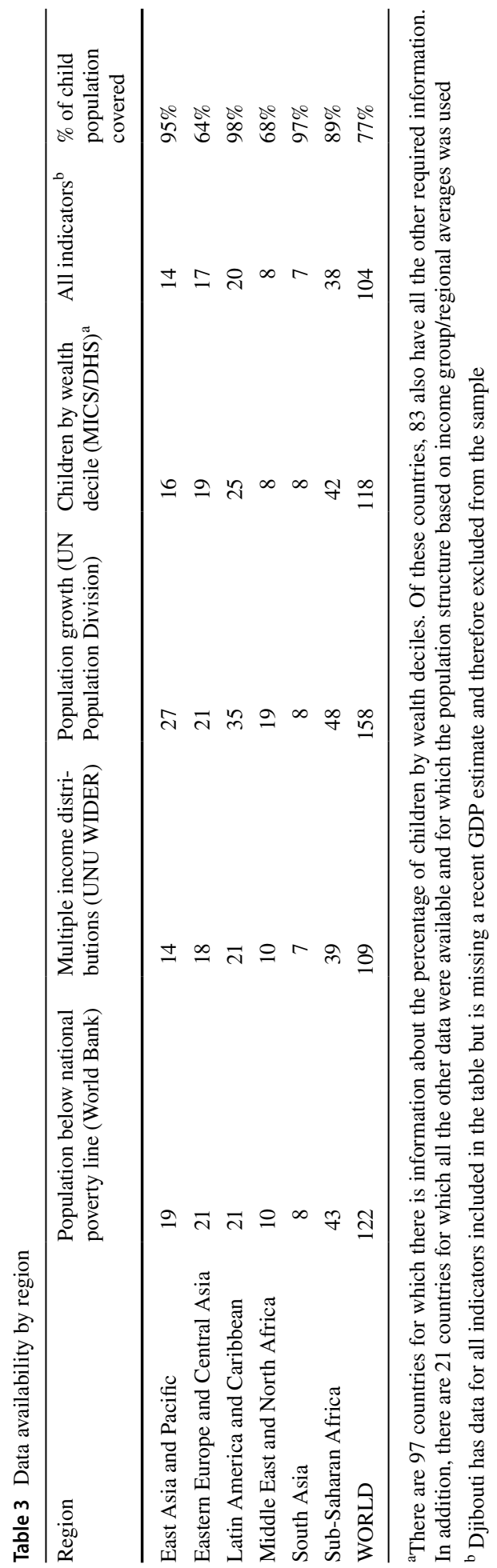


would have had to avoid using some observations or go through a process of reconversion/ conversion of their data. However, as Jolliffe and Prydz used the same levels of monetary poverty headcount as we did, there is no need to engage in such an exercise. Our interest is in analyzing changes in the distribution of children living in MPHs within each country, not the comparison of monetary poverty levels across countries.

Thus, the first step is to establish the poverty line in terms comparable to the average income per decile. The UNU WIDER database allows to distribute the total GDP in the country among deciles (given the share of each decile in total income) and thus calculate the average income per decile. We move up the deciles until we reach the level that coincides with the proportion of persons whose income/consumption is below the poverty line. If the poverty headcount is an odd multiple of five, we establish the poverty line at the level of per capita income of the corresponding decile (e.g. if the headcount is $35 \%$, we establish the poverty line at the value of per capita income of the fourth decile). If the poverty headcount is a round multiple of ten, we set the poverty line at the midpoint between the average per capita income in the deciles above and below the headcount (e.g. the fourth and fifth deciles if the headcount is $40 \%$ ). We used a similar interpolation in other cases, except for poverty headcounts below 5\%, in which case we applied the average per capita income of the first decile.

Then, we combine the proportion of the population living below the national poverty line and the proportion of children by decile. ${ }^{6}$ We apply the cumulative share of children across deciles to the respective poverty headcount. In other words, let us assume there are 100 persons in the country and that 45 of them are children (i.e. children are 45 percent of the total population). Let us also assume that monetary poverty is 30 percent (i.e. 30 persons). Also, let us assume that the proportion of children in the bottom 30 percent of the population is 50 percent (and not 45 percent as in the total population). Then, out of the 30 monetary poor persons, 15 are children. This means that one third of the children live in MPHs. The number of children living in MPHs is 15 and the total number of children is 45 . Thus, out of the 45 children, 15 (or one in three) live in MPHs.

In other words, we add up the share of children (out of the total child population, as explained above) in each decile until we reach the poverty headcount. Obviously, and similarly to establishing the poverty line, when the monetary poverty headcount rate does not exactly match a round multiple of ten, we apply the relevant share for the residual decile. For instance, if a country has a poverty headcount of 45 percent, we sum the share of children in the first four deciles and add 50 percent of the fifth decile.

Although this is, to the best of our knowledge, the first attempt to estimate globally the percentage of children in MPHs using national poverty lines, other authors have carried out similar exercises using the PPPU\$ 1.25 and PPPU\$ 1.90 metrics estimated by the World Bank. Most recently, World Bank and UNICEF (2020) estimated that 17.5 per cent

\footnotetext{
${ }^{6}$ As explained above, MICS and DHS provide information about distribution of children across wealth (not income/consumption) deciles. These are based on the well-known Filmer-Pritchett (Filmer and Pritchett 1998, 2001) wealth asset index which combines information from various items in the household (e.g. bicycle, radio, construction materials of walls, etc.). They use principal component analysis in order to rank households from poorest to richest (see also Hancioglu 2005; Gordon and Nandy 2012 for alternatives, limitations and historical review of earlier, similar exercises). Obviously, assuming the distribution of children among wealth and among income/consumption deciles is similar, as we do when we apply these proportions to the distribution of households by income/consumption deciles from the UNU WIDER database, is a strong one. As explained above it is the best option, given the data limitations.
} 
of children struggle to survive with less than PPPU\$ 1.90 per day, that 41.5 percent of children live in households with income/consumption of less than PPP U\$ 3.20 per day, and that 66.7 percent of them are in households with income/consumption lower than PPP U\$ 5.50 per day. Batana et al. (2013) show how the prevalence of monetary poverty (overall and by age) are affected by assumptions about equivalence of scale. ${ }^{7}$ Newhouse et al. (2017) provide regional estimates ${ }^{8}$ also using different equivalence scales to compare the headcount for the whole population and for children. As their data are more recent, we also carried out the exercise described above using the World Bank estimates of the prevalence of poverty based on PPP U\$ 1.90 (instead of the national poverty the lines as above). Our results come close to their estimates. This is a validation of the methodology and syntax used in our analysis, as it allows us to reproduce their results. In a way this is not surprising. Their results are aligned ${ }^{9}$ with the ones presented in UNICEF (2000) which used Total Fertility Rate by wealth quintile/deciles to estimate regional headcounts of children in MPHs (based on the available evidence at that time).

We build the regional and global estimates from the bottom up (i.e. country-bycountry). There are 104 countries (see Table 3) for which we have all the required information (monetary poverty rates, child population distribution of children per wealth deciles, income distribution to measure the prevalence of monetary poverty, past income distributions to simulate change of distribution due to economic shock, and GDP per capita). For a further 18 countries, we have monetary poverty rates - and therefore a baseline estimate - but lack country-specific information that would allow us to simulate the impact of COVID-19. For those countries, we calculate the percentage changes observed in other countries in the region and apply those to the existing baseline. For a final 37 countries we do not have either information and impute the regional average (weighted by child population) when calculating regional and global estimates. $^{10}$

\section{The Impact of COVID-19 on Children Living in Poor Households by the End of 2020 and End of 2021}

To assess the impact of COVID-19 on the number of children living in poor households, we distinguish two effects. One is a per capita income effect, representing the average

\footnotetext{
7 Deaton and Paxson (1997) have also made this point. Household composition and intra-household allocation are important too. However, as Batana et al (2013) recognize, both data and conceptual models to deal with these issues need further development (see also World Bank 2018). Cognizant of this, and partly because we do not use microdata, our estimates assume equal distribution of resources within the household, no economies of scale, and the same equivalence scale for all the household members. It is too early in the pandemic and there are no microdata available for most countries to do otherwise. A notable exception is Martin et al. (2020) who analyze the impact of unemployment and cash transfers on poverty but only in the San Francisco area (in the United States, a rich and data-rich, country).

8 The two main differences between their estimates and ours (and the reason why we do not take their regional estimates as a baseline) is that (a) we use national poverty lines and (b) we have country-by-country data which they do not provide.

${ }^{9}$ Clearly, they are different, given the time elapsed between the estimates. However, in terms of the proportion between overall and child poverty prevalence, the numbers are strikingly similar.

10 Alternatively, it would be possible to directly estimate weighted regional averages without regard to countries which may have some of the data but missing other information. However, the method described above is more accurate as it takes into account all country-specific evidence we may have and is therefore used in this paper.
} 
decline in income per person. ${ }^{11}$ The other one is a distribution effect, considering changes to the underlying income distribution. In the following, we explain both effects more in detail. Although the effects were estimated separately, for practical and conceptual reasons, as they are intertwined in the real world, we do not present them separately and only show the final result. ${ }^{12}$

First, we calculate the income effect. COVID-19 has already led to an extraordinary global economic decline. This has severe effects on household incomes and consumption. We use the latest country-by-country estimates of real gross domestic products change between 2019 and 2020 (as well as between 2020 and 2021) from both the IMF (2020) and the World Bank (2020a). We take the lowest GDP growth or largest GDP decline for a country (irrespective of whether it is from the IMF or the World Bank), for the "pessimistic" scenario. We take the smallest GDP decline or largest GDP growth for a country for the "optimistic" scenario. We adjust the estimates of total real GDP with population growth (United Nations Population Division 2019) ${ }^{13}$ in each year to calculate the change in real per capita GDP for each year and scenario. This national rate of change is applied to the per capita income of each decile. Contrasting these to the previously established poverty line determines the estimated or projected new level of poverty absent changes in income distribution.

Second, we consider a distribution effect by calculating differential rates of per capita income change for different deciles. In the current pandemic situation, it is safe to assume the decline in income is worse for the lowest end of the income distribution. ${ }^{14}$ Informal workers (and even formal ones at the lower end of the pay-scale) do not have the option to work from home and many petty traders and small business are closing down, leaving their (usually not well-paid workers) without income. ${ }^{15}$ This assumption is strongly supported by recent evidence; workers hardest hit by the current crisis are least likely to work remotely (see Brussevich et al. 2020). In like manner, Furceri et al. (2020) find that recent epidemics have raised inequality, lowered the shared of incomes going to the bottom deciles, and lowered the employment-to-population ratio for those with basic education. Lakner et al. (2019) simulated the effect of changes in inequality (measured by the Gini coefficient) on the proportion of people living below the World Bank line of $\$ 1.90 /$ day PPP, showing that a $1 \%$ annual change in a country's Gini index has a larger impact on global poverty than a $1 \mathrm{pp}$ change of the annual growth rate. While estimates for the impact of COVID-19 on extreme poverty model changes in the Gini

\footnotetext{
11 This is based on projections of annual rates of economic growth. Thus, the results refer to end-of-year projections for both 2020 and 2021.

12 We do not model the mitigating impact of social protection and other policy interventions, nor further possible negative effects like reductions in remittances from family members in richer countries to relatives in poorer countries (for this see Zambrana Cruz and Rees 2020).

13 We use the average annual rate of change for their "middle" projection.

14 Arndt et al. (2020) and Lustig et al (2020) also present evidence supporting our assumption of a more unequal income distribution in various contexts and using different methodologies. Interestingly, this assumption does not automatically lead to increases in poverty prevalence - even when there is an overall decline in GDP per capita. The following scenario is plausible: per capita income declines but not much, the prevalence of poverty is high, and there is a shift in income from the bottom to mid- and upper-deciles. In such case there could be sufficient income gains among people just below the poverty line to reduce the prevalence of poverty. Such scenario is not only plausible, it happens in two countries in our simulation.

15 Another effect might be at play. During the financial, food and fuel crisis of the 2008-2010 period, poorer and rural workers did not suffer as much as the urban middle class (e.g. see Kielem 2020). In such cases, income distribution may become more egalitarian but due to reductions of income among the better off rather than improvement among the worse off. Clearly, not a good outcome.
} 
coefficient, they likely miss more complex changes along the income distribution (World Bank 2020c).

To model per capita income rates of change for different deciles (i.e. to arrive at a less equal income distribution), we used historical evidence on world income inequality from UNUWIDER (2020) database. Specifically, we collected information on the share of income per decile. First, we looked for changes on income distribution caused by the Global Financial Crisis 2008/2009. ${ }^{16}$ Although not all countries had information for these years, we used the ones we found. As a second option we used data for the most recent changes in income distribution. For countries where income distribution has been becoming more egalitarian, we assumed the crisis would reverse the gains of the last few years (i.e. whichever the most recent years we could obtain were used). For a third group of countries, the only available data were changes further back in time but not related to the 2008/2009 crisis. ${ }^{17}$ Our use of previous economic contractions may in fact underestimate the impact of the current crisis on income distribution: ILO (2020) estimates that workers in developing and emerging economies, especially those engaged in informal work, have been affected to a much greater extent (in terms of working-hour losses) than in past crises.

Assuming a constant GDP per capita, but using these estimated shares per decile, allows us to obtain a new (simulated) average income per decile. Contrasting these to the previously established poverty line determines the estimated or projected new level of poverty due purely to changes income distribution. The idea is to apply the (less egalitarian) shares of income per decile to the new (lower) national average income to obtain the combined effect.

Before doing that, there is a further issue related to the paucity of income distribution data. As mentioned above, few countries have annual data, most have gaps of various years in between data points. The average time span between years for which income distribution data exist is about 5 years across countries. Thus, a reasonable option would be to normalize the effect in every country to the equivalent of a five-year period to make them comparable.

However, income distribution may change quickly in a short period (and then remain constant or fluctuate sharply back). It could also steadily become more (or less) unequal. Thus, we explored the average annual rate of change of income shares in each country (i.e. independently of the number of years between observations). ${ }^{18}$ This we could use with more confidence to simulate the impact of COVID-19 on monetary poverty between 2019 and 2020.

Moreover, it is important to ensure that the resulting simulated changes in income shares by decile resemble the historically observed changes in income distribution. Consequently, we converted the shares of income per decile into a Gini coefficient. Fortunately, the UNU WIDER and World Bank database also provides Gini coefficients so we could control that our approximation is correct.

We recalculate the Gini coefficients for those selected income distributions and compare the yearly change to the regional averages of yearly Gini changes seen across the last

\footnotetext{
${ }^{16}$ Depending on data availability, we tried to identify one income distribution before and after the Global Economic Crisis 2008/2009 to assess changes to the income distribution.

17 In all cases we look at absolute changes and income distribution becoming less egalitarian, as the idea is to have informed assumptions about the order of magnitude that specific countries have experienced in terms of changes in income distribution.

18 Obviously, in the absence of further information, we do not know if we are comparing two peaks of a fluctuating income distribution or a trough and a peak.
} 
20 years (World Bank 2020b). We inspect the range (maximum and minimum) annual average rate of change, as well as the interquartile range, the median, and the mean. For some countries, the absolute value of the annual rate of change was too large. We could not safely assume that it would have been representative of the likely distributional effect of the pandemic and the measures to control it. Thus, we explored and compared the results of leaving all countries with whatever values the historical trends provided, by using only half or a third of the change for all countries, and using only the actual values of the countries with the relatively smaller changes and capping those that were relatively higher. We tried adjusting the rate of change of any country for which the rate of change exceeded ${ }^{19}$ the $75^{\text {th }}$ percentile of the changes, or the median, or the mean (i.e. if their rate of change was "too high", the value was set at the regional "maximum" of the mean, median or third quartile).

Obviously, using the full (historically observed) annual rate of change provides the maximum potential change. We complement this outer bound (for a given pessimistic or optimistic projection of GDP) with the results of two further distributional effects. In summary, we obtain three scenarios: a) full distribution effect, b) mild distribution effect, and c) least distribution effect, which are as follows:

a) Full distribution effect: we do not adjust the percentage change identified based on historical data.

b) Mild distribution effect: any distribution of income shares by decile that resulted in Gini coefficients changes exceeding the 75th percentile of observed changes in Gini across the same world region was capped at the 75th percentile level and all changes in decile shares adjusted proportionally.

c) Least distribution effect: any distribution of income shares by decile that resulted in Gini coefficients changes exceeding the median of observed changes in Gini across the same world region was capped at the median level and all changes in decile shares adjusted proportionally.

Bringing income and distribution effects together, we simulated different scenarios, ranging from very optimistic to very pessimistic. We distinguished in the end between five scenarios when calculating the impact of COVID-19 in 2020, estimating the potential effect for two upper and two lower bounds as well as a middle scenario. Figure 3: Graphical representation of scenarios presents the various scenarios and their underlying assumptions.

In addition, the various economic outlooks by the World Bank and the IMF also provide economic projections for 2021, pointing to a slight recovery of the world economy. Thus, we extend our model an extra year to estimate the consequences this may have on children living in monetary poor families. We identify five scenarios for 2021 , which are a continuation of the equivalent estimates in 2020 and are based on path dependency ${ }^{20}$ (i.e. the most optimistic scenario for 2021 starts where the most optimistic scenario ended in 2020, the most pessimistic scenario for 2021 starts where the most pessimistic

\footnotetext{
19 The other countries kept their historical values.

${ }^{20}$ Lower bound (outer) for 2021: Optimistic GDP growth, Least distribution effect; opposite effect (more egalitarian), but 33\% of effect in 2020. Lower bound (inner) for 2021: Optimistic GDP growth; Mild distribution effect; opposite effect (more egalitarian), but $20 \%$ of effect in 2020. Middle Average GDP growth for 2021: No change of income distribution. Upper bound (inner) for 2021: Pessimistic GDP growth; Mild distribution effect; same effect (less egalitarian), but $20 \%$ of effect in 2020. Upper bound (outer) for 2021: Pessimistic GDP growth; Full distribution effect; same effect (less egalitarian), but 33\% of effect in 2020.
} 


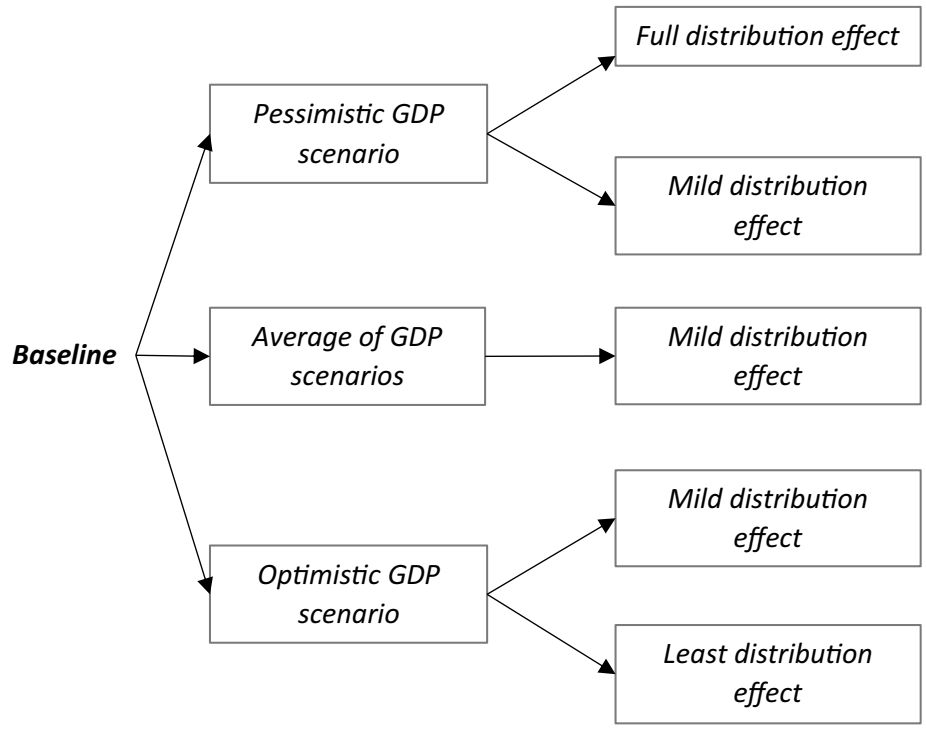

\author{
Upper bound \\ (outer) \\ Upper bound \\ (inner) \\ Middle \\ Lower bound \\ (inner) \\ Lower bound \\ (outer)
}

Fig. 3 Graphical representation of scenarios

scenario ended in 2020, etc.). In other words, we project two successive scenarios instead of a one off, two-years period. The income effect is based on country-by-country 2021 projections by IMF (2020) and the World Bank (2020a) and the same logic in terms of using the most optimistic/pessimistic projection from either agency per country. The distribution effect follows the equivalent exercise carried out for $2020 .^{21}$ In the two optimistic scenarios, we also assume we may see a reversal of some of the distribution changes which occur in 2020. This follows the "reversal" logic of the growth projections. Some of the increase in income distribution disparity expected in 2020 is softened. This does not mean that we think that income distribution always becomes more unequal during recessions and that it becomes more equal during recoveries. The historical experience does not bear such conclusion. However, if income distribution were to continue deteriorating in 2021 as GDP recovers, the resulting level of children MPHs would be confined within our estimated boundaries. ${ }^{22}$

\title{
Conclusions and Suggestions for Further Work
}

It is well known that children suffer poverty differently from adults. Their needs, expectations, and aspirations are different. As children are not supposed to earn a living, it is important to assess directly their material shortcoming and deprivations - in other words, to measure child poverty multidimensionally. Nevertheless, in the context

\footnotetext{
21 We explored fractions (at 75, 66, 50, 33, 25, and 20 percent) of the projected change in 2020 . We settled on 33 and 20 percent as the ones that had more impact on the final results.

22 We did check that there is no distribution effect (within the historical experience) that would convert a pessimistic (or optimistic) scenario based on GDP changes into an optimistic (or pessimistic) scenario in terms of children in MPHs.
} 
of the current pandemic, as parents lose their jobs and source of income, it is also important to measure what happens to children living in monetary poor and impoverished families.

About a third of the children in developing countries were living in MPHs before COVID-19. As families see their income dwindle, their home and work circumstances turned upside down due to the socioeconomic impacts of COVID-19, and their employment prospects dissipate, children are at high risk to be in MPHs. There could be between 713 and 735 million children in these circumstances in low- and middle-income countries by the end of 2020 and between 668 and 735 by the end of 2021, absent action to prod families facing employment and financial hardship. These numbers represent increases of 20-24 percent by the end of 2020 and of 13-24 by the end of 2021 (compared to 2019).

Clearly, the wider range for 2021 is the result of wider variability in the projections of the underlying data further into the future. More than half of these children live in subSaharan Africa and South Asia. The headcount rates are highest in Sub-Saharan Africa and Latin America. The highest percentage increases in the numbers of children are likely to occur in Central and East Asia.

As mentioned, these calculations do not take into account the social protection measures that approximately 212 countries have implemented as a response to the crisis (Gentilini et al. 2020), many of them with focus on families with children. In the future, when new household surveys become available, our estimations would inform to what extent those measures were able to contain the increase of children living in monetary poverty.

The future research agenda will also include estimating extreme poverty and the depth of monetary poverty, which would be helpful to estimate both the impact and the required amounts of monetary support households would need to avoid monetary poverty. In addition, there is need for further disaggregation of these results among and within households (e.g. by age groups, gender, and urban and rural areas) and across countries (e.g. by level of income or Human Development Index, by fragility, and by presence of conflicts/humanitarian situations). The impact of policy interventions as well as the result of reduced remittances on children in MPHs should also be scrutinized further.

Finally, the calculations for the pre-COVID scenario, to our knowledge the first global estimation of the prevalence of children living in monetary poor households in the developing world using national poverty lines, will serve as a baseline for future analysis on this particular aspect of the situation of children. In particular, as for measuring child poverty it is important to use a direct multidimensional approach, a future analysis will explore the overlap for children and adolescents who are multidimensionally deprived as well as living in monetary poor households in developing countries.

\section{References}

Arndt C, Davies R, Gabriel S, Harris L, Makrelov K, Modise B, Robinson S, Simbanegavi W, van Seventer D, Anderson L (2020) Impact of Covid-19 on the South African economy - an initial analysis. SATIEDWorking Paper \# 11

Barnes H, Wright G (2012) Defining child poverty in South Africa using the socially perceived necessities approach. In: Minujin A, Nandy S (eds) Global child poverty and well-being: measurement, concepts, policy and action. Policy Press, Bristol

Batana Y, Bussolo M, Cockburn J (2013) Global extreme poverty rates for children, adults and the elderly. Econ Lett 120(3):405-407 
Boyden J, Hardgrove A, Knowles C (2012) Continuity and change in poor children's lives: evidence from young lives. In: Minujin A, Nandy S (eds) Global child poverty and well-being: measurement, concepts, policy and action. Policy Press, Bristol

Brussevich M, Dabla-Norris E, Khalid S (2020) Who will bear the brunt of lockdown policies? Evidence from tele-workability measures across countries. IMF Working Paper No. 20/88

Deaton A, Paxson C (1997) Poverty among children and the elderly in developing countries. Working Papers 226. Princeton University, Woodrow Wilson School of Public and International Affairs, Research Program in Development Studies

Filmer D, Pritchett L (1998) Education attainment of the poor (and rich): DHS evidence from around the globe. World Bank Working Paper, Washington D. C.

Filmer D, Pritchett L (2001) Estimating wealth effects without expenditure data - or tears: an application to educational enrollments in states of India. Demography 38(1):115-132

Furceri D, Loungani P, Ostry J, Jonathan D, Pizzuto P (2020) Will Covid-19 affect inequality? Evidence from past pandemics. Covid Economics 12:138-157

Gentilini U, Almenfi M, Dale P, Palacios R, Natarajan H, Rabadan GAG, Okamura Y, Blomquist J, Abels M, Demarco G, Santos I (2020) Social protection and jobs responses to COVID-19: a real-time review of country measures (September 18, 2020) (vol 2): global database on social protection and jobs responses to COVID-19. COVID-19 living paper, World Bank Group, Washington, D.C. http://documents.worldbank.org/curated/en/330791600474275156/Global-Databaseon-Social-Protection-and-Jobs-Responses-to-COVID-19. Accessed Oct 2020

Gordon D, Nandy S (2012) Measuring child poverty and deprivation. In: Minujin A, Nandy S (eds) Global child poverty and well-being: measurement, concepts, policy and action. Policy Press, Bristol

Hancioglu A (2005) Performance of alternative approaches for identifying the relatively poor and linkages to reproductive health. In: Lerner Susana, Vilquin Eric (eds) Reproductive health, unmet needs and poverty: issues of access and quality of services. Committee for International Cooperation in National Research in Demography, Paris

ILO - International Labor Organization (2020) ILO monitor $6^{\text {th }}$ edition: COVID-19 and the world of work

IMF (2020) World economic outlook, October 2020: a long and difficult ascent. https://www.imf.org/en/ Publications/WEO/Issues/2020/09/30/world-economic-outlook-october-20202020/09/30/world-econo mic-outlook-october-2020. Accessed Nov 2020

Jolliffe D, Prydz E (2016) Estimating international poverty lines from comparable national thresholds. Policy Research Working Paper 7606. World Bank

Jones N, Sumner A (2011) Child poverty, evidence, and policy: mainstreaming children in international development. Policy Press, Bristol

Kielem A (2020) Child poverty and economic shocks in Togo: policies matter. In: Nebie G et al (eds) Child poverty and social protection in western and Central Africa. CROP and Ibidem-Verlag, Stuttgart

Lakner C, Mahler DG, Negre M, Prydz E (2019) How much does reducing inequality matter for global poverty. World Bank Policy Research Working Paper 8869

Lustig N, Pabon VM, Sanz F, Younger S (2020). The impact of COVID-19 lockdowns and expanded social assistance on inequality, poverty and mobility in Argentina, Brazil, Colombia and Mexico. CGD Working Paper 556. Center for Global Development, Washington, DC

Lyytikäinen K, Jones N, Huttly S, Abramsky T (2006) Childhood poverty, basic services and cumulative disadvantage: an international comparative analysis. Young lives working paper no. 33. Young Lives and Save the Children Fund UK, London

Martin A, Markhvida M, Hallegatte S, Walsh B (2020) Socio-economic impacts of COVID-19 on household consumption and poverty. Economics of Disasters and Climate Change: 1-27

Newhouse D, Suárez Becerra P, Evans M (2017) New global estimates of child poverty and their sensitivity to alternative equivalence scales. Econ Lett 157(C):125-128

Nieuwenhuys O (1994) Children's lifeworlds: gender, welfare and labour in the developing world. Routledge, London

United Nations Population Division (2019) World population prospects: 2019 revision

UNU WIDER (2020) World income inequality database, April 2020 update

World Bank (2018) Poverty and shared prosperity 2018: piecing together the poverty puzzle. Washington DC

Wordsworth D, McPeak M, Feeny T (2005) Understanding children's experience of poverty: an introduction to the DEV framework. Children and Poverty Working Paper 1. Christian Children's Fund, Richmond

World Bank (2020a) Macro Poverty Outlook. https://www.worldbank.org/en/publication/macro-povertyoutlook. Accessed 23 Oct 2020 
World Bank (2020b) World development indicators. https://data.worldbank.org/indicator/SI.POV.GINI and https://data.worldbank.org/indicator/SI.POV.NAHC. Accessed 31 May 2020

World Bank (2020c) World Bank blogs. https://blogs.worldbank.org/opendata/impact-covid-19-coronavirus-global-poverty-why-sub-saharan-africa-might-be-region-hardest. 31 October 2020

World Bank and UNICEF (2020) Global estimate of children in monetary poverty: an update. World Bank Poverty and Equity Discussion Paper.http://documents1.worldbank.org/curated/en/966791603123453 576/pdf/Global-Estimate-of-Children-in-Monetary-Poverty-An-Update.pdf. Accessed Oct 2020

Zambrana Cruz G, Rees G (2020) A lifeline at risk: COVID-19, remittances and children. UNICEF Office of Research - Innocenti, Florence

Publisher's Note Springer Nature remains neutral with regard to jurisdictional claims in published maps and institutional affiliations. 